Published at www.cmaj.ca between Sept. 14 and Sept. 21

\section{Dispelling myths}

$\mathrm{T}$ he relentless upward spiral of drug costs in Canada would be reversed if a long-recommended public drug insurance plan was finally introduced, according to a new study commissioned by the Canadian Centre for Policy Alternatives.

The study, The Economic Case for Universal Pharmacare, Costs and Benefits of Publicly Funded Drug Coverage for all Canadians, argues that universal pharmacare is a "way to control costs through efficient pharmacoeconomic assessment of new drugs and by developing bargaining power when dealing with powerful transnational companies" (www.policyalternatives.ca /sites/default/files/uploads/publications /National\%20Office/2010/09/Universal _Pharmacare.pdf).

Political fears that a national drug insurance plan would have runaway costs are "completely lacking in substance," while there is no evidence to support the proposition that high prices inspire industry to invest in research in Canada, adds the study. Noting that the Patented Medicines Prices Review Board (PMPRB) says the ratio of pharmaceutical research \& development to sales was a mere $7.5 \%$ in Canada in 2009 , the study concludes that "Canada's pharmaceutical policies are a total failure. Many Canadians do not have equitable access to medicines, and the lack of coverage makes some treatments inefficient due to lack of compliance. The whole system is unsustainable because we cannot control the growth of drug costs."

"Although Canada deliberately sets its drug prices high to encourage research and development on Canadian soil, total R\&D spending by the industry is $\$ 1.31$ billion, $59 \%$ of which consists of tax subsidies. The PMPRB's policy has therefore been a complete failure, since it leads Canadians to spend $\$ 1,530$ million more than the average prices of brand-name drugs in OECD [Organisation for Economic Cooperation \& Development] countries in order to generate $\$ 537$ million in $\mathrm{R} \& \mathrm{D}$ spending. Canada would benefit greatly from using this money instead to encourage pharmaceutical $R \& D$ by funding new types of incentives - for example through public spending in pharmaceutical research or the implementation of a prize-system for innovation. It may be reasonable to maintain alternative industrial policies for this sector, but artificially increasing drug costs is extremely costly and fails to foster pharmaceutical innovation in Canada."

The study estimates that Canada could shave $\$ 10.7$ billion per year of its \$25-billion per year drug bill and bring prices in line with international averages by introducing pharmacare. "If Canada chooses to get rid of industrial policies that artificially inflates drug costs in order to implement competitive purchasing (in the same way that New Zealand does, for example), Canadians could save more than $\$ 10$ billion on the cost of their prescription drugs."

Canada could save $\$ 1.43$ billion per year alone if the PMPRB used different countries in determining the cap at which it sets the prices of brand-name drugs, the study adds. Another \$1.31 billion per year could be saved if other provinces followed Ontario's lead and eliminated industry kickbacks to pharmacies for using generic drugs.

"A strong and pro-active pharmacoeconomic drug assessment program" would be needed to ensure that the most cost-effective drugs are placed on provincial formularies and ensure that "a culture of evidence-based medicine" is instilled among physicians, says the study, conducted by Marc-André Gagnon, assistant pofessor of public policy at Carleton University in Ottawa, Ontario.
"A comparison of Canada with other OECD countries reveals that Canada can be considered an inefficient model in terms of drug policy: 1) we spend more per capita on drugs, the costs of which are growing faster than elsewhere; 2) our public plans are inequitable because they do not provide adequate or suitable coverage to a large number of Canadians; and 3) the meager industrial benefits in the pharmaceutical sector are totally out of proportion with the money given by Canadians in various privileges and subsidies to the industry," the study concludes." - Wayne Kondro, CMAJ

\section{Ombudsman urges ban against isolating mentally-ill prisoners}

$\mathrm{R}$ ound-the-clock health care coverage in prisons, improved suicide prevention training for security guards and a prohibition against isolating mentally ill prisoners for extended periods of time are among measures which should be introduced in the nation's prisons to prevent more deaths in custody, says Correctional Investigator of Canada Howard Sapers.

Paying lip service to recommendations that have been identified by a number of prison studies and investigations won't yield change, Sapers says in his last quarterly report on his investigation into 9 of the 131 deaths that occurred in federal custody between October 2007 and August 2010.

"The preservation of life is an integral part of the mandate of the Correctional Service. I expect this principle to be embedded in policy, reflected in the culture of the organization and orient its day-to-day interactions with offenders. The preservation of life involves an integrative 'continuum of care' perspective. It requires heightened and continued vigilance and it cannot be done in isolation, in a piecemeal or silo 
fashion. All sectors of the CSC [Correctional Service of Canada] - security, health services, case management, programming, staff training, research and education - must work together in a common purpose," Sapers says in his report, Final Assessment of the Correctional Service of Canada's Response to Deaths in Custody

Sapers added that his investigation into nine of the deaths found "common deficiencies in the following areas: response to medical emergencies; sharing of information between clinical and front-line staff; monitoring of suicide pre-indicators; quality/frequency of security patrols, rounds and counts; management of mentally ill offenders; (and) quality of internal investigative reports and processes."

"From a preventative standpoint, there are some particularly high risk areas that require a rigorous internal review and accountability framework - the use of segregation and solitary confinement to manage offenders at risk of suicide and the application of physical restraints to manage self-injurious offenders come immediately to mind," he states in the report (www .oci-bec.gc.ca/rpt/oth-aut/oth-aut20100 908-eng.aspx).

To redress the deficiencies, Sapers makes seven recommendations:

"1. I recommend that the Service develop a comprehensive public accountability and performance framework to ensure sustained progress in addressing factors related to preventing deaths in custody.

2. I recommend that the Service provide 24 hour per day / 7 days per week health care coverage at all maximum, medium and multi-level institutions.

3. I recommend that basic information and instruction for managing offenders at risk of self-injury or suicide be shared with front-line staff so as to ensure effective monitoring, crisis response strategies and prevention protocols are easily and readily accessible.

4. I recommend that the quality of security patrols be enhanced by introducing audit and accountability measures to ensure rounds and counts are conducted in a manner consistent with preservation of life principles.

5. I recommend that the practice of placing mentally ill offenders at risk of suicide or serious self-injury in prolonged segregation be prohibited.

6. I recommend that the Service strengthen its national investigative framework to ensure principles of independence, accountability and transparency are entrenched in the review of lessons learned and implementation of corrective actions. To that end, National Boards of Investigation involving suicide and serious self-injury should be chaired by an external health care professional and their reports be made public.

7. I recommend that the Service create a senior management position exclusively responsible for promoting, monitoring and ensuring Safe Custody practices." - Wayne Kondro, $C M A J$

\section{Geneticists urge use of public health data to attract genetics research}

$\mathrm{P}$ opulation-level public health data in the province of Ontario should be used as a "lever" to attract international investment in genetics research, a high-powered panel of geneticists urges.

But to lead the anticipated revolution in medicine that genetics research is expected to create, Ontario will have to build data systems that allow scientists to readily access patient records for research purposes, the geneticists argued at a symposium convened by the Gairdner Foundation in Toronto, Ontario, in September.

The Ontario health care system represents one of North America's largest health care data-gathering systems, making it attractive to international investors in genetics research, said Leroy Hood, president of the Institute for Systems Biology in Seattle, Washington.

But Hood, who is credited with leading the development of DNA and protein sequencers, warned that technology choices will be critically important as Ontario develops its systems of personal health records for patients, electronic health records for physicians, and system-wide electronic medical records linking hospitals and other points of care.

"The worst thing you could do in some ways would be to follow old digital approaches to the medical records," he said. "Because what you do is you spend a zillion bucks, you get to the end, and in five years you have to throw them out. We need to create an IT [information technology] system that can seamlessly transfer from basic research to translational medicine."

If Ontario can succeed in this, Hood and the other Gairdner panelists agreed, the payoff could be vast.

"I don't think people realize what a precious opportunity exists here," said Stephen Friend, president of Sage Bionetworks in Seattle. "This is one of the three or four places in the world where the investment in pulling something together is getting close to critical mass."

Lon Cardon, senior vice-president genetics for GlaxoSmithKline, stressed that Ontario's "huge sample base of 13 million individuals" is highly attractive to investors in genetics research. The province should aim to be "that one place in North America to really own this area," he added.

"You are going there anyway," Cardon said. "Lead it, and I think you'll have people join in." - Paul Christopher Webster, Toronto, Ont.

\section{Alberta announces framework to boost patient safety}

patient safety advisory panel,
an adverse event reporting
system and a patient safety network are among six strategies unveiled by the Health Quality Council of Alberta and the provincial government on Sept. 20 to improve patient safety.

The patient/family safety advisory panel, which will report to the quality council, will weigh in on systemic issues of patient safety and approaches to informing patients of their role in receiving safe care. The panel will be 
made up of, although not limited to, patients who have experienced harm as a result of health care services.

To mitigate and monitor that harm, the new Patient Safety Framework for Albertans also mandates the creation of a provincial system to track and evaluate adverse events and close calls (www.hqca.ca/assets/pdf/Sept20/HQC A\%20Patient\%20Safety\%20Framewo rk\%20081010.pdf).

Currently, formal investigations of adverse events are undertaken through a variety of different mechanisms in Alberta, including quality assurance committees and other investigations through the Public Health Act, Health Care Protection Act, Fatalities Inquiries Act, Health Professions Act and coun- cil regulations under the Regional Health Authorities Act.

The reporting system will be designed to mesh with other provincial and national systems as they evolve.

The provincial patient safety network will be established under the Health Quality Council of Alberta to identify and report on strategies for system improvements and measurement of patient safety. The network will also review the impact of health care policies on patient safety, and will be made up of health care service experts, academics, legal expertise and members of the public.

The council will also develop a safety management plan to guide health care organizations and professional regulatory colleges on best practices in patient safety. The framework calls upon these organizations to develop policies and procedures to support a "just and trusting culture," that would emphasize reporting and disclosing adverse events. The sixth strategic initiative identified under the strategy is to "build knowledge capacity to support patient safety."

The goal is to create a safer system for patients, said Alberta Health and Wellness Minister Gene Zwozdesky, in a release (www.hqca.ca/assets/pdf/Sept 20/HQCA\%20news\%20release\%20Se pt\%2020\%202010_FINAL.pdf).

"Albertans deserve a safe and effective health care system that they can rely on." - Lauren Vogel, CMAJ

DOI:10.1503/cmaj.109-3683 